\title{
Diode Laser Cyclophotocoagulation
}

\author{
Subrata Mandal, Ritu Gadia, Jatin Ashar \\ Dr RP Center for Ophthalmic Sciences, All India Institute of Medical Sciences, New Delhi, India
}

\section{INTRODUCTION}

Cyclodestructive procedures are generally used for refractory glaucomas. Previously it has been carried out by various methods like surgical excision of ciliary body, ${ }^{1}$ cyclodiathermy, ${ }^{2,3}$ cycloirradiation, ${ }^{4}$ cycloelectrolysis, ${ }^{5}$ cyclocryotherapy, ${ }^{6-9}$ ultrasound, ${ }^{10}$ microwave cyclodestruction, ${ }^{11}$ and currently by cyclophotocoagulation. Laser cyclophotocoagulation has now become the principal method of cyclodestrive procedures. Various lasers has been used for this purpose which includes ruby, Nd:YAG, argon, krypton and diode laser, etc. Beckman and Sugar first popularized the use of trans-scleral cycpophotocoagulation (TSCPC) by ruby laser in early 1970s. ${ }^{12,13}$ Later they discovered that Nd:YAG laser was more effective in penetrating sclera and energy absorbed by ciliary body is also optimum. ${ }^{13}$

Secondary glaucomas like postpenetrating keratoplasty glaucomas, aphakic/pseudophakic glaucomas, neovascular glaucomas and glaucoma following trauma are examples where cyclodestructive procedures are favored due to a poor response to standard filtering procedures. ${ }^{14-16}$

\section{INDICATIONS FOR CYCLODESTRUCTIVE PROCEDURES}

1. Refractive primary ACG, OAG.

2. Neovascular glaucoma (NVG).

3. Post-traumatic glaucoma.

4. Aphakic/pseudophakic glaucoma especially with ACIOLs (anterior chamber IOLs).

5. Severe congenital glaucoma with multiple failed surgeries.

6. Postpenetrating keratoplasty glaucoma.

7. Postretinal detachment surgery glaucoma.

8. Silicone oil induced glaucoma.

9. Inflammatory glaucoma.

10. Glaucoma with severe conjunctival scarring.

11. Failed trabeculectomy and drainage implants.

12. Medical condition precluding invasive surgery.

13. Patients' refusal to undergo invasive surgery.

14. Emergent situations (i.e. acute onset NVG).

\section{CURRENT METHODS OF CYCLOABLATION}

1. Contact (transcleral) cycloablation

- Cyclocryotherapy
- Diode

- Nd:YAG

2. Noncontact cycloablation

- Nd:YAG

- Diode

3. Transpupillary argon green cyclophotocoagulation

4. Endolaser ablation

- Diode

- Argon

\section{MECHANISM OF ACTION}

Various theories have been described regarding mechanism of cyclophotocoagulation.

\section{Decreased Aqueous Production}

- Destruction of the ciliary epithelium resulting in decreased aqueous production.

- Destruction of ciliary blood vessels and coagulative necrosis also contributes in decreasing aqueous production (ciliary body ischemia). ${ }^{17}$

- Intraocular inflammation is also thought to be responsible for short-term hypotension. ${ }^{18}$

- Creation of transscleral flow similar to cyclodialysis

- Increased uveoscleral outflow.

For both of these mechanisms presence of ciliary body pigment is important in absorbing laser energy. ${ }^{19}$ The diode laser $(810 \mathrm{~nm}$ ) has greater melanin absorption compared to the Nd:YAG laser (532 nm).

\section{Increased Aqueous Outflow}

- Nd:YAG laser also produces a neuroepithelial defect resulting in increase outflow which is related to the extent of treatment. In an in vitro perfusion model, laser lesions placed $6 \mathrm{~mm}$ posterior to limbus had an equivalent effect on outflow to that of laser lesions directed towards ciliary process. ${ }^{20}$

An animal study ${ }^{21}$ suggests that the decrease of intraocular pressure after pars plicata cyclocoagulation resulted from the reduction of aqueous secretion, whereas that after pars plana cyclocoagulation resulted from enhancement of the uveoscleral outflow through the enlarged extracellular space from the anterior chamber into the suprachoroidal space. 


\section{CYCLOPHOTOCOAGULATION TECHNIQUES}

\section{Transscleral Cyclophotocoagulation with the Nd:YAG Laser}

In pulsed mode Nd:YAG laser focuses very intense laser energy into small area for a short period which produces mechanical photodisruption. But in continuous mode it creates 1000 fold greater energy than used for routine photodisruption. These high energy levels alter the ciliary body thermally and are used for transscleral cyclophotocoagulation. ${ }^{22}$

Transscleral cyclophotocoagulation with the Nd: YAG laser can be performed both as continuous and pulsed laser system. It may be a contact and noncontact procedure. ${ }^{23-25}$ Contact system uses hand held probe, which is placed on conjunctiva to allow energy transmission directly to the ocular surface. Noncontact laser system transits the laser energy through air from a slit lamp delivery system. Contact procedure requires a lesser energy than the noncontact procedures. The commonly used settings in the thermal mode of Nd: YAG noncontact method employs 8 Joules for $20 \mathrm{msec}$, 32-40 spots over $360^{\circ}$. In comparison the contact technique requires 7 Watts for 0.7 seconds for each spot; 32-40 spots being applied over $360^{\circ}$ (Table 1). In noncontact method laser applications have to be placed 1.5-2.0 mm from limbus. Whereas in case of contact method anterior edge of probe is placed 0.5 to $1 \mathrm{~mm}$ posterior to limbus. However the YAG laser is bulky, expensive and requires careful maintenance.

The success rate of Nd:YAG laser Cyclophotocoagulation in various studies is listed in Table 2.

\section{Clinical Trials}

In a large series of 500 patients by Shields $\mathrm{MB}$ et $\mathrm{al}^{26}$ suggest that noncontact transscleral Nd:YAG cyclophotocoagulation is the cyclodestructive procedure of choice. It offers a reasonable surgical option in patients with neovascular glaucoma, glaucomas with active uveitis, glaucomas in aphakia or pseudophakia, and other cases in which filtering surgery has failed or is felt to have a low chance for success. Satisfactory intraocular pressure reduction was achieved in $62 \%$ of the patients with one treatment session and with multiple treatments in 94\%. However, visual loss remains a significant postoperative complication occurring in 39\% of the study population. Patients

Table 1: Treatment parameters for Nd:YAG laser cyclophotocoagulation

\begin{tabular}{lll}
\hline & Noncontact & Contact \\
\hline Energy & $4-8 \mathrm{~J}$ & $4-9$ watts \\
Duration & $10-20 \mathrm{msec}$ & $0.5-0.7 \mathrm{secs}$ \\
Number & 32 spots & 32 spots \\
Circumference & $360^{\circ}$ & $360^{\circ}$ \\
Spot size & Fixed, $70 \mu \mathrm{m}$ & Fixed, Quartz probe \\
\hline
\end{tabular}

Table 2: Success rates in various studies using Nd: YAG cyclophotocoagulation

\begin{tabular}{lrcccc}
\hline Authors & $\begin{array}{c}\text { No. } \\
\text { of } \\
\text { eyes }\end{array}$ & $\begin{array}{c}\text { Follow- } \\
\text { up } \\
\text { (months) }\end{array}$ & $\begin{array}{c}\text { Success } \\
\text { definition } \\
\text { (mm Hg) }\end{array}$ & $\begin{array}{c}\text { Suc- } \\
\text { cess } \\
\text { rate } \\
(\%)\end{array}$ & $\begin{array}{c}\text { Retreat- } \\
\text { ments } \\
\text { (eyes) }\end{array}$ \\
\hline Phelan MJ et al $^{28}$ & 10 & 15 & 21 & 50 & 7 \\
Delgado MF et al $^{29}$ & 115 & 27 & 22 & 65 & 33 \\
Beiran I et al $^{30}$ & 52 & 12 & 21 & 70 & - \\
Schuman JS et al & 116 & 12 & 22 & 65 & 31 \\
Schuman JS et al & & & & 59 & 16 \\
Miyazaki et al $^{35}$ & 140 & 6 & $5-22$ & 59 & 12 \\
Hampton C et al $^{36}$ & 106 & 6 & $7-20$ & 51 & 29 \\
Brancato et al $^{37}$ & 23 & 8.6 & 25 & 66 & 13 \\
Klapper et al $^{38}$ & 30 & 6 & 22 & 86 & 7 \\
\hline
\end{tabular}

with neovascular glaucoma had the greatest percentage of visual loss at $46 \%$, compared with $34 \%$ and $38 \%$ for patients with glaucomas in pseudophakia and aphakia, respectively. But it is not known how many of these cases of visual loss were a direct result of the cyclophotocoagulation

A prospective study by Lin $\mathrm{P}$ et $\mathrm{al}^{27}$ of 68 eyes of 64 patients with advanced, uncontrolled glaucoma who received cyclophotocoagulation showed a significant reduction of IOP after surgery at 1, 5, and 10 years of follow-up; however, $51.5 \%$ of eyes failed by the end of 10 years, with most failures occurring within the first year (40\%).

Ten eyes of pediatric glaucoma was treated by Phelan MJ et $\mathrm{al}^{28}$ with Nd:YAG contact transscleral laser cyclophotocoagulation. Five patients (50\%) achieved IOP of less than 21 mm but Hg was in, retreatment was required in 7 of 10 eyes. Loss of vision was seen in four patients, and one case of phthisis bulbi was noted.

Delgado MF et $\mathrm{al}^{29}$ did noncontact transscleral Nd:YAG cyclophotocoagulation treatment for neovascular glaucoma in 115 eyes of 111 subjects treated. Success rate was $65.0 \%$ at 1 year, $49.8 \%$ at 3 years, and $34.8 \%$ at 6 years. Phthisis developed in $8.6 \%$ of the eyes.

Results of noncontact transscleral Nd:YAG cyclophotocoagulation in the treatment of postpenetrating keratoplasty refractory glaucoma is also promising. In Beiran's series of fifty-two eyes, the mean post-treatment IOP was 15.8+/-9.7 $\mathrm{mm} \mathrm{Hg}$, pretreatment IOP being 38.7+/-11.9 mm Hg. The probability of a graft remaining clear was $79 \%$ at 1 year and $56 \%$ at 5 years. ${ }^{30}$ But in another study out of 25 patients with clear grafts before cyclophotocoagulation, 11 (43-44\%) had graft decompen-sation. ${ }^{31,32}$

\section{Transscleral Cyclophotocoagulation with Diode Laser}

The ergonomics of the semiconductor Diode laser have made it a better alternative to the Nd: YAG laser. ${ }^{39}$ Moreover the 
Diode laser at $830 \mathrm{~nm}$ has a better absorption by the pigmented tissue of the ciliary body, requiring lesser energy per spot. Histopathologic studies have shown the diode laser to produce most of its coagulative effect on the ciliary body stroma. It requires less energy than Nd:YAG laser (4.0 J vs. $1.2 \mathrm{~J}$ ). ${ }^{39}$ Of the various cyclodestructive laser procedures semiconductor diode sys-tems appear to possess the best combination of effectiveness, portability, expense, and ease of use at present time. The procedure is performed in the outpatient clinic. Contact method is superior as it has the advantages of reduced scattering and increased scleral transmission. The response of ciliary body destruction is thought to be gauged by the 'Pop' sound. Although there have been few comparisons between the Diode and YAG laser, but postlaser pain and chances of persistent hypotony are greater with the Nd:YAG laser. Settings used for contact mode in one of the largest studies on 210 eyes were 1.5 Watts for 1.5 seconds using 40 spots over $360^{\circ}$ (Figs 1 and 2). The probe is to be placed with its edge at the limbus, but is actually centred 1.2 mm posterior to the limbus in the region of the ciliary body (Fig. 3). Other authors prefer to keep the power just below the level at which 'Pop' sound is heard (Table 3). The contact method uses a $\mathrm{G}$ probe (Figs 4 to 6 ) which is designed to deliver energy $1.2 \mathrm{~mm}$ from the limbus and has a small protrusion that indents the conjunctiva and sclera to optimize delivery.

Common complications following Diode laser cyclophotocoagulation are conjunctival burns, mild postoperative inflammation and atonic pupil. Uncommonly there may be severe uveitis, and loss of vision and rarely hyphema and vitreous hemorrhage. The success rate of DLCP in various studies is listed in Table 4.

\section{Clinical Trials}

Agarwal HC et $\mathrm{al}^{40}$ evaluated contact and noncontact methods of diode laser delivery and found using an energy setting of $3 \mathrm{~J}$ per spot, both were equally effective in lowering IOP in eyes with refractory glaucoma.

Lai JS et $\mathrm{al}^{41}$ evaluated the efficacy and safety of diode laser transscleral cyclophotocoagulation in the treatment of 14 patients of chronic angle-closure glaucoma. The total success rate defined as IOP $<21 \mathrm{~mm} \mathrm{Hg}$ with or without medication(s) was $85.7 \%$ at 1 year of follow-up. Two eyes required repeat treatment. Seven eyes (50\%) had atonic pupil following the laser treatment.

A retrospective analysis by Murphy CC et al ${ }^{42}$ of 263 eyes of 238 patients of refractory glaucoma who underwent transscleral diode laser cyclophotocoagulation at two centers showed $89 \%$ of patients achieved an IOP of less than $22 \mathrm{~mm}$ Hg or a greater than $30 \%$ drop in IOP after cyclodiode therapy. Hypotony occurred in $9.5 \%$ of patients, $76 \%$ of whom had neovascular glaucoma.
Table 3: Treatment parameters for diode laser cyclophotocoagulation

\begin{tabular}{lll}
\hline & Noncontact & Contact \\
\hline Energy & 1.2 watts & 1.5 watts \\
Duration & 990 msec & 1.5 seconds \\
Number & 40 spots & $25-30$ spots \\
Circumference & $360^{\circ}$ & $360^{\circ}$ \\
\hline
\end{tabular}

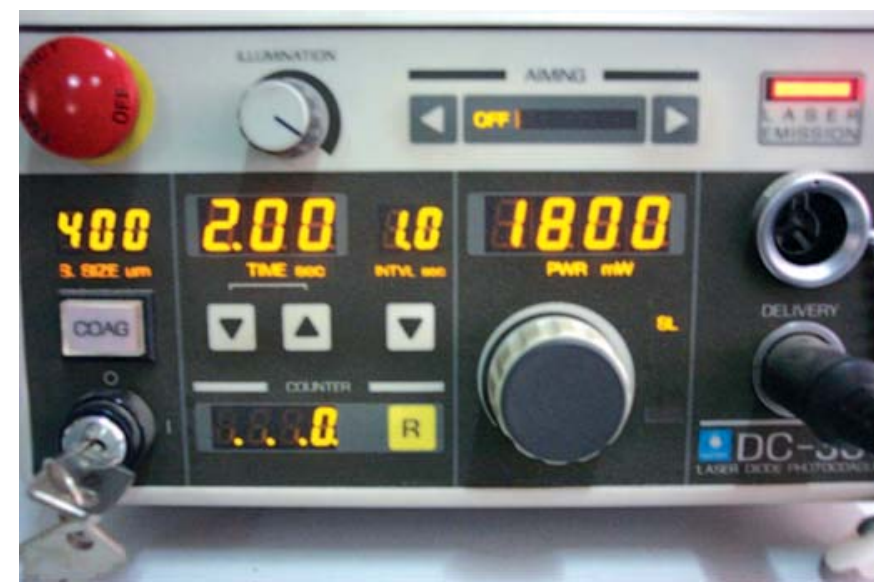

Fig. 1: DLCP machine (Nidek)

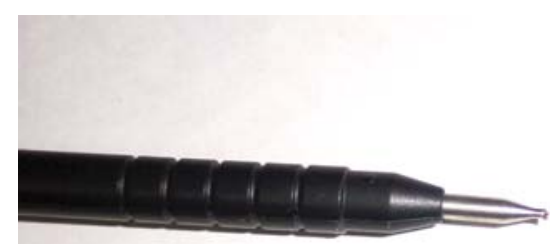

Fig. 2: DLCP probe (Nidek)

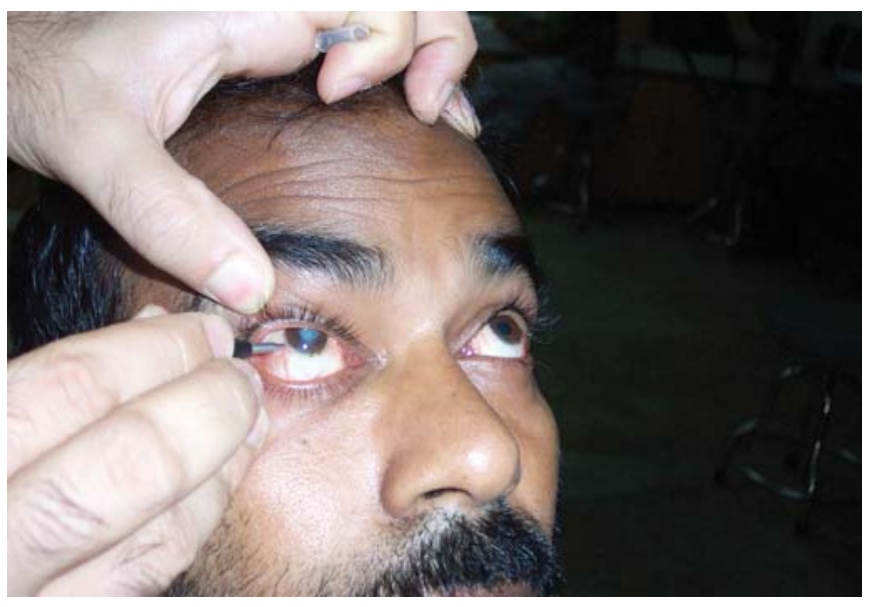

Fig. 3: DLCP being done 


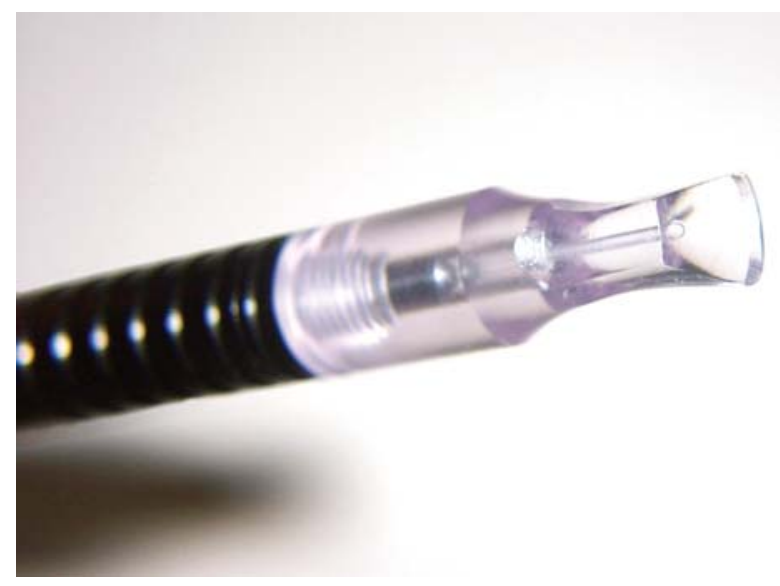

Fig. 4: IRIS G-probe (side view)

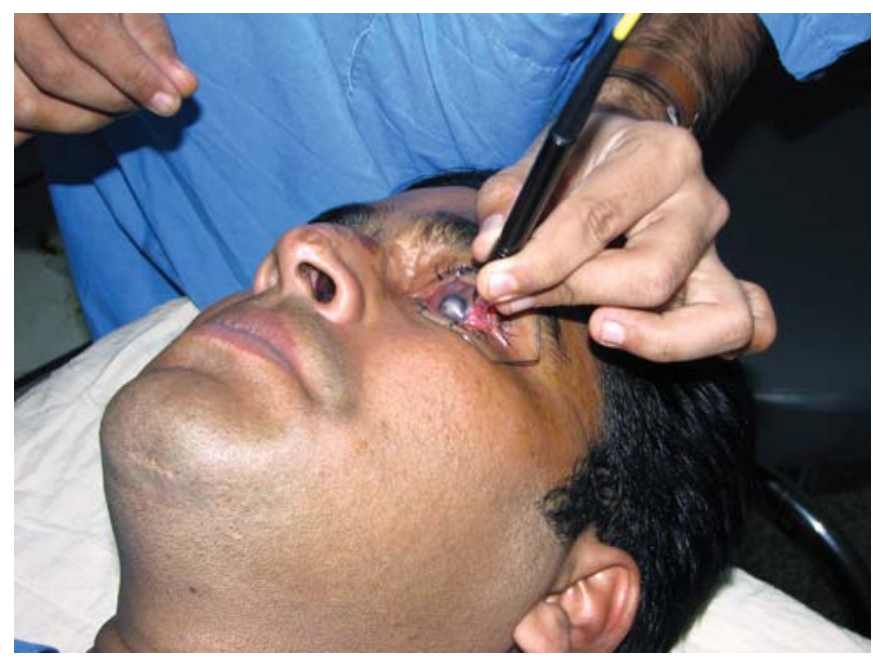

Fig. 6: DLCP being done with G-probe

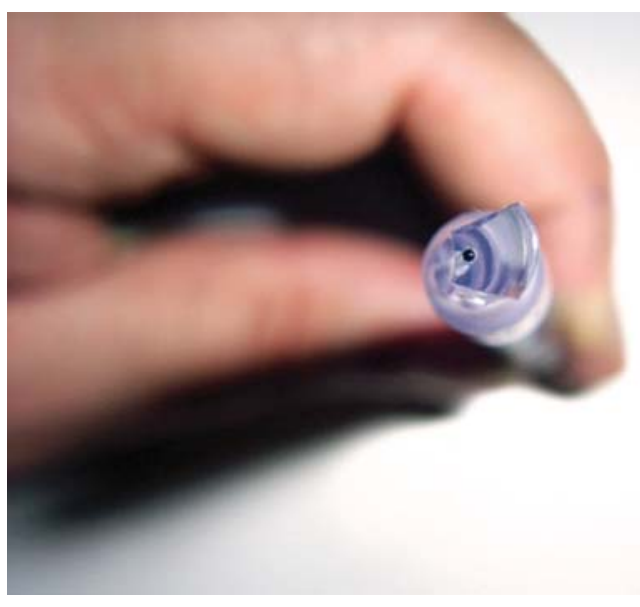

Fig. 5: IRIS G-probe (end on view)

Kramp K et $\mathrm{al}^{43}$ evaluated transscleral diode laser contact cyclophotocoagulation in the treatment of different glaucomas, also as primary surgery in 193 eyes. The IOP was successfully controlled (final IOP $10-22 \mathrm{~mm} \mathrm{Hg}$ ) in $76.4 \%$ of cases after a single or multiple TSCPC treatments. The best results were obtained among the patients with POAG, in the oldest age group and in those patients without any previous or subsequent glaucoma operations. The proportion of eyes requiring multiple treatments was $21.2 \%$. There was a complication rate of $14.4 \%$, mostly mild uveitis. Phthisis bulbi occurred in three eyes (1.6\%).

In Schlote's ${ }^{44}$ series of 100 eyes overall success rate was $74.2 \%$. A high success rate was achieved in inflammatory glaucoma (75\%), primary open-angle glaucoma (89.5\%), and neovascular glaucoma $(86.7 \%)$ whereas the results were

Table 4: Success rates in various studies using diode laser cyclophotocoagulation

\begin{tabular}{|c|c|c|c|c|c|}
\hline Authors & No. of eyes & $\begin{array}{l}\text { Follow-up } \\
\text { (months) }\end{array}$ & $\begin{array}{l}\text { Success definition } \\
(\mathrm{mm} \mathrm{Hg})\end{array}$ & Success rate & $\begin{array}{l}\text { Retreatments } \\
\text { (eyes) }\end{array}$ \\
\hline Lai JS et $\mathrm{al}^{41}$ & 14 & 12 & 21 & $85.7 \%$ & 2 \\
\hline Schlote $\mathrm{T}$ et $\mathrm{al}^{44}$ & 100 & 12 & $5-21$ & $74.2 \%$ & - \\
\hline Kumar $\mathrm{A}$ et $\mathrm{al}^{48}$ & 21 & 6 & $<24$ & $100 \%$ & 13 \\
\hline Autrata $\mathrm{R}$ et $\mathrm{al}^{50}$ & 69 & 12 & $\leq 21$ & $79 \%$ & - \\
\hline Wong EY et $\mathrm{al}^{51}$ & 33 & 9.4 & 22 & $56 \%$ & - \\
\hline Kosoko et $\mathrm{al}^{52}$ & 27 & 12 & $<23$ & $72 \%$ & - \\
\hline Bloom et $\mathrm{al}^{53}$ & 210 & 10 & $<22$ & $66 \%$ & 102 \\
\hline \multirow[t]{2}{*}{ Spencer et $\mathrm{al}^{54}$} & 58 & 19 & $<22$ & $81 \%$ & 26 \\
\hline & & & $<17$ & $59 \%$ & \\
\hline \multirow[t]{2}{*}{ Werner et $\mathrm{al}^{55}$} & 106 & 24 & $<22$ & $85 \%$ & 23 \\
\hline & & & Pain relief & & \\
\hline Pucci et $\mathrm{al}^{56}$ & 120 & 26 & $<22$ & $54 \%$ & 55 \\
\hline Noureddin et $\mathrm{al}^{57}$ & 36 & 12 & $<21$ & $72 \%$ & 9 \\
\hline Ocakoglu et $\mathrm{al}^{58}$ & 32 & 11.4 & $<22$ & $56 \%$ & 14 \\
\hline Gupta V et al ${ }^{59}$ & 52 & 12 & $<22$ & $92 \%$ & 22 \\
\hline Levinger $\mathrm{E}$ et $\mathrm{al}^{60}$ & 33 & 12 & 22 & $73 \%$ & - \\
\hline Mistlberger $\mathrm{A}$ et $\mathrm{al}^{61}$ & 206 & 9 & 22 & $72.7 \%$ & 33 \\
\hline
\end{tabular}


relatively poor in traumatic glaucoma (57.1\%), aphakic glaucoma (57.1\%), and congenital or juvenile glaucoma (62.5\%).

Role of diode laser cyclophotocoagulation in the management of refractory pediatric glaucomas is also good. With repeated treatment, cyclodiode can provide effective control of IOP pediatric glaucomas though the success rate is lower than with adults. Younger eyes may recover from treatment more rapidly but it has a lower rate of severe adverse effects than surgical modalities and has a role as a temporizing measure, as an adjunct to surgery, or in managing selected patients in whom surgery is undesirable because of a high risk of surgical complications. ${ }^{45}$

Inflammatory glaucoma is still a diagnostic and therapeutic dilemma and surgical intervention is always associated with a high risk of failure. Schlote $\mathrm{T}$ et $\mathrm{al}^{46}$ showed a success rate of $77.3 \%$ (72.2\% of those with uveitic glaucoma). DLCP may become the surgical procedure of choice in treating secondary glaucoma caused by chemical injury and also in scleritis associated glaucoma, using reduced parameters for application.

Semchyshyn TM et $\mathrm{al}^{47}$ assessed the outcome of supplemental transscleral diode laser cyclophotocoagulation in twenty-one eyes with uncontrolled IOP despite the presence of an aqueous tube shunt and maximally tolerated glaucoma medica-tions and found that adjunctive transscleral diode cyclophoto-coagulation treatment(s) is a viable option to lower IOP in these cases.

Patients with medically uncontrolled glaucoma persisting after intravitreal silicone oil removal can be treated with TSCP; however, the reduction of IOP is variable. The IOP usually falls after a mean of 2-3 sittings of DLCP. ${ }^{48}$ Patients with medically uncontrolled glaucoma secondary to intravitreal silicone oil injection can also be treated with TSCPC in spite of the retained intravitreal silicone oil. ${ }^{49}$

Autrata $\mathrm{R}$, et $\mathrm{al}^{50}$ evaluated the long-term results of transscleral cyclophotocoagulation in refractory pediatric glaucoma patients. With repeat cyclophotocoagulation, $79 \%$ of the eyes had a clinically effective reduction in IOP $(</=21 \mathrm{~mm} \mathrm{Hg})$ for 1 year with a low risk of severe complications. Aphakic patients had an increased risk of postoperative complications.

Wong $\mathrm{E} \mathrm{Y}$ et $\mathrm{al}^{51}$ studied the effectiveness and safety of diode laser contact transscleral cyclophotocoagulation in Asian patients with refractory glaucoma by lower energy settings with an innovative probe featuring a glass ball tip that focused the laser beam onto the ciliary body and found it to be relatively effective and safe.

The variability in the clinical response to DLCP stems from the following facts:

- Variability in the pressure exerted over the sclera

- Differences in scleral thickness

- Variation in probe inclination.

\section{Krypton Laser Cyclophotocoagulation}

The layer absorbing greatest amount of energy is the pigmented epithelium of the ciliary body analogous to the role of retinal pigment epithelium, presumably, although there has been no experimental study on absorption of laser energy by the ciliary body. A large proportion of krypton laser energy is absorbed by the pigmented epithelium and then radiate to the nonpigmented epithelium of ciliary body. Though it has a poor scleral transmission its good absorption by the pigmented epithelium makes it a potentially useful method for cyclophotocoagulation. Settings used for krypton laser photocoagulation are 300 to $500 \mathrm{~W}$ energy for 10 seconds using 10 spots over $90^{\circ}$ for $360^{\circ}$ (Table 5). Krypton produces comparable lesions at the ciliary body in an experimental study in rabbits with half the energy required by the Nd: YAG laser. ${ }^{62}$ An advantage of the method is that standard retinal krypton photocoagulators can be used for the procedure.

Table 5: Treatment parameters for krypton laser cyclophotocoagulation

\begin{tabular}{ll}
\hline & Transscleral \\
\hline Energy & 300 to $500 \mathrm{~W}$ \\
Duration & 10 seconds \\
Number & 10 per quadrant \\
Circumference & $90-360^{\circ}$ \\
\hline
\end{tabular}

\section{Clinical Trials}

Raivio VE et al ${ }^{63}$ evaluated krypton laser for transscleral contact cyclophotocoagulation (CPC) in the treatment of glaucoma in young patients. The treatment was delivered by means of a fiberoptic probe with compression of the sclera by the probe and followed up for 2 years. After one or more krypton CPCs, but no other glaucoma procedures, an IOP level of 8 to $21 \mathrm{~mm}$ $\mathrm{Hg}$ or a decrease in IOP of more than 30\% was obtained in 14 of 22 (64\%) eyes at the last follow-up. No permanent hypotony, phthisis bulbi, or devastating CPC-related complications were noted.

Raivio VE et $\mathrm{al}^{64}$ also evaluated the krypton laser for transscleral contact cyclophotocoagulation in the treatment of post-traumatic glaucoma. With one or more cyclophotocoagulation treatments, the IOP decreased from the baseline mean (+/- standard deviation) of $32.6+/-12.8 \mathrm{~mm}$ Hg to 21.8 $+/-7.5 \mathrm{~mm} \mathrm{Hg}(\mathrm{n}=13)$ at 3 months, and to $19.6+/-10.5 \mathrm{~mm}$ $\mathrm{Hg}(\mathrm{n}=18)$ at the last visit (mean 19.4 months; range, 3 weeks to 73 months) after cyclophotocoagulation but no other glaucoma procedure. One (6\%) case of phthisis occurred. It was concluded that because of the refractory nature of the disease, repeated treatments may be needed.

Di Staso $S$ et $\mathrm{al}^{65}$ studied the role of transscleral cyclophotocoagulation in neovascular glaucoma (NVG) 
treatment with krypton laser on 12 eyes of 12 patients. Six months after treatment, intraocular pressure was down enough for the pain to disappear.

\section{Endoscopic Cyclophotocoagulation (ECP)}

ECP is a new technique to directly photocoagulate the ciliary body under endoscopic guidance. The ciliary body can be treated directly within the eye using argon laser light delivered through a 20-gauge fiberoptic probe placed through a pars plana port. The endolaser probe uses an illumination source, 4.5 lux video camera, and gives a 70 degree field of view. The optimal focal distance for the laser is $0.75 \mathrm{~mm}$. A cotton-tipped applicator is used to indent the sclera and bring the ciliary processes into view through a dilated pupil. ${ }^{66-69}$ The end of the probe is placed about $3 \mathrm{~mm}$ from the ciliary body. This procedure is not commonly used because it is invasive. It may have some advantages in the management of postpenetrating keratoplasty glaucoma and neovascular glaucoma. ${ }^{70,71}$

Newer endoscopic systems that incorporate a viewing fiberoptic $^{71}$ as well as a laser fiberoptic are available, which permits the ciliary body to be visualized on a television screen. Endoscopic laser endocyclophotocoagulation can be performed at the time of cataract extraction. ${ }^{72}$ The iris is lifted with a viscoelastic material, and the anterior portions of ciliary processes are treated. It can also be done at the time of vitrectomy, for example, in a diabetic patient with neovascular glaucoma and a vitreous hemorrhage.

The two main approaches to reach the ciliary process are via a limbal or parsplana entry. In limbal approach cyclophotocoagulation is done through a temporal and nasal limbal entry for nasal $180^{\circ}$ and temporal $180^{\circ}$ respectively. In parsplana approach after doing a limited three port anterior vitrectomy ECP probe is introduced through each superior port for opposite ciliary process treatment. ${ }^{68}$ The procedure can be done with argon or diode laser (Table 6).

Table 6: Treatment parameters for argon green laser cyclophotocoagulation

\begin{tabular}{lll}
\hline & $\begin{array}{l}\text { Endoscopic } \\
\text { (limbal or pars plana) }\end{array}$ & $\begin{array}{l}\text { Transpupillary } \\
\text { (slit-lamp based) }\end{array}$ \\
\hline Energy & $500-1000 \mathrm{~mW}$ & $500-1000 \mathrm{~mW}$ \\
Duration & $0.1-0.2 \mathrm{sec}$ & $0.1-0.2 \mathrm{sec}$ \\
Number & $3-5$ per ciliary process & $\begin{array}{l}3-5 \text { per ciliary process } \\
\text { Circumference }\end{array}$ \\
Spot size & Fixed 20 gauge probe & 50-200 $\mu \mathrm{m}$ \\
\hline
\end{tabular}

The advantages of endoscopic cyclophotocoagulation include decreased energy requirement, inflammation and collateral tissue damage. While, complications such as phthisis, chronic hypotony, and retinal detachment have rarely been reported, most ophthalmologists reserve ECP for cases of refractory glaucoma, in pseudophakic or aphakic patients, given a lack of established treatment parameters with this approach. Also the procedure because of its intraocular nature carries an increased risk for endophthalmitis and therefore needs to be performed in the operation theater. Moreover there is still no uniform agreement on the degree of cycloablation that needs to be performed in each sitting and when the procedure needs to be repeated. Till the time further studies clarify the missing questions it is advisable that 180 to 270 degrees of the ciliary processes should only be ablated in a single sitting.

IOP lowering following endoscopic cyclophotocoagulation takes anytime between 1-4 weeks.

The success rate of endoscopic cyclophotocoagulation in various studies is listed in (Table 7).

Table 7: Success rates in various studies using endolaser cyclophotocoagulation

\begin{tabular}{lccccc}
\hline Authors & $\begin{array}{c}\text { No. } \\
\text { of } \\
\text { eyes }\end{array}$ & $\begin{array}{c}\text { Follow- } \\
\text { up } \\
\text { (months) }\end{array}$ & $\begin{array}{c}\text { Success } \\
\text { definition }\end{array}$ & $\begin{array}{c}\text { Success } \\
\text { rate }\end{array}$ & $\begin{array}{c}\text { Retreat- } \\
\text { ments } \\
\text { (eyes) }\end{array}$ \\
\hline Chen J et al $^{70}$ & 68 & 12.9 & $21 \mathrm{~mm} \mathrm{Hg}$ & $90 \%$ & 5 \\
Uram et al $^{72}$ & 10 & 8.8 & $21 \mathrm{~mm} \mathrm{Hg}$ & $90 \%$ & 0 \\
Gayton JL et al $^{73}$ & 58 & 24 & $19 \mathrm{~mm} \mathrm{Hg}$ & $65 \%$ & 4 \\
\hline
\end{tabular}

\section{CLINICAL RESULTS}

Chen $\mathrm{J}$ et $\mathrm{al}^{70}$ performed endoscopic cyclophotocoagulation which encompassed 180 to 360 degrees of the ciliary body circumference in 68 eyes through a limbal incision. Ninety percent of eyes achieved an intraocular pressure $<$ or $=21 \mathrm{~mm}$ $\mathrm{Hg}$ from a mean preoperative value of $27.7+/-10.3 \mathrm{~mm} \mathrm{Hg}$. Best-corrected visual acuity was stable or improved in 64 eyes (94\%), with four (6\%) losing 2 or more lines of Snellen acuity. No case of hypotony (intraocular pressure $<5 \mathrm{~mm} \mathrm{Hg}$ ) or phthisis was observed.

Uram et $\mathrm{al}^{71}$ treated 10 patients with intractable neovascular glaucoma by parsplana ECP to coagulate between 90 to 180 degrees of ciliary processes. With a mean follow-up of 8.8 months, the IOP was reduced from a mean preoperative level of $43.6 \mathrm{~mm} \mathrm{Hg}$ to a mean of $15.3 \mathrm{~mm}$ Hg postoperatively. Nine of the 10 eyes (90\%) were able to achieve an IOP $<21 \mathrm{~mm} \mathrm{Hg}$ with three of those eyes requiring glaucoma medication. The only major complication encountered was hypotony in two eyes, although both had chronic retinal detachments.

Uram et al ${ }^{72}$ also described 10 patients who had combined phacoemulsification, ECP, and intraocular lens (IOL) implantation. After phacoemulsification, 180 degrees of ciliary processes were treated before insertion of the posterior chamber IOL. After a mean follow-up of 19.2 months, the mean IOP was reduced to $13.5 \mathrm{~mm} \mathrm{Hg}$ from a mean preoperative IOP of $31.4 \mathrm{~mm}$ Hg. There were no significant complications except a transient vitreous hemorrhage that was noted on the second postoperative day. 
Gayton JL et al ${ }^{73}$ conducted a randomized prospective study on 58 eyes of 58 patients comparing endoscopic laser cycloablation performed through a cataract incision at the time of cataract surgery with combined trabeculectomy and cataract surgery. At the final available visit of 2 years follow-up, 30\% of endoscopic laser patients achieved intraocular pressure control (below $19 \mathrm{~mm} \mathrm{Hg}$ ) without medication and 65\% with medication. Forty percent of trabeculectomy patients achieved control without medication and 52\% with medication. It was concluded that combined endoscopic cycloablation and cataract surgery provided a viable alternative to phacotrabeculectomy in the management of patients with cataract and coexistent glaucoma.

Neely DE et al ${ }^{74}$ retrospectively review 51 endoscopic diode laser cyclophotocoagulation procedures performed on 36 eyes of 29 pediatric patients with glaucoma over a 6-year period. Whereas baseline mean pretreatment IOP was $35.06+/-8.55$ $\mathrm{mm} \mathrm{Hg}$ final postoperative IOP was $23.63+/-11.07 \mathrm{~mm} \mathrm{Hg}$. Nine eyes (25\%) were retreated at least once. Cumulative success rate after all procedures at last follow-up was $43 \%$. Aphakic patients had an increased risk of postoperative complications including retinal detachment in 2 patients, hypotony in 1 patient, and progression of vision loss from hand motion to no light perception in 1 patient.

In postpenetrating keratoplasty glaucoma, ECP has also been shown to be an effective treatment and may have advantages over transcleral cyclophotocoagulation. In study by Lin SC et al 10 patients who had penetrating keratoplasties (PKPs) were treated by ECP to control their IOP. ${ }^{70}$ The IOP control rate (IOP $<22 \mathrm{~mm} \mathrm{Hg}$ ) was $80 \%$ at last follow-up consisting of 30 months from the time of PKP. There were no corneal graft failures. In comparison, several studies evaluating transscleral cyclophotocoagulation treatment of keratoplasty associated glaucoma have demonstrated a high rate of graft failure after laser. ${ }^{31,32}$

Lima FE et al ${ }^{75}$ compare endoscopic cyclophotocoagulation (ECP) and the Ahmed drainage implant in the treatment of refractory glaucoma. Their success rate at 24 months was $70.59 \%$ and $73.53 \%$ for the Ahmed and ECP groups, respectively and difference was not significant. The eyes that underwent Ahmed tube shunt implantation had more complications than those treated with ECP.

Lin SC et al ${ }^{76}$ studied the acute and chronic vascular effects of endoscopic cyclophotocoagulation (ECP) versus transscleral cyclophotocoagulation (TCP) in a rabbit model. Histopathologically they confirmed the overall greater vascular occlusion seen with TCP. They concluded that chronic poor perfusion of the ciliary body after TCP may account, in part, for its efficacy, as well as the significant complications including hypotony and phthisis.

One advantage of ECP is surgeon can ablate ciliary process under direct visualization which is particularly helpful in cases of severe congenital glaucoma. In congenital glaucoma because of enlargement of eyeball ciliary processes may be displaced resulting in failure of transscleral cyclophotocoagulation. ${ }^{74}$ Barkana $\mathrm{Y}$ et al ${ }^{77}$ reported a case of congenital glaucoma where IOP was effectively lowered with ECP while repeated transscleral DLCP failed. They showed both misplaced laser burn as well as viable ciliary process over correctly placed laser burn.

The main disadvantage of ECP is that it is an intraocular procedure with the probable risks of penetrating surgeries. Endophthalmitis, choroidal hemorrhage, and retinal detachment though rare, but remain potential complications ${ }^{68}$ Hence, although ECP may be a preferable surgery in cases of refractory glaucoma with relatively intact vision, it is better to avoid in eyes with very poor vision, since it would unnecessarily expose them to such potential complications. It should be done in an operation theater and not as an office procedure.

\section{Transvitreal Cyclophotocoagulation}

This method of cyclophotocoagulation is performed in conjunction with vitrectomy. Procedure is performed after direct visualization through operating microscope of ciliary processes after scleral depression. It requires a clear media and aphakia or pseudophakia. After anterior vitrectomy, endolaser is inserted through same port as used for vitrectomy. After doing limited parsplana anterior vitrectomy endolaser probe is inserted through same port for ciliary ablation while ciliary process is visualized through pupil by depressing sclera ${ }^{68}$ Argon or diode laser can be used. $66,69,78$

Patel $\mathrm{A}$ et $\mathrm{al}^{66}$ did vitrectomy and transvitreal endophotocoagulation of the ciliary processes to treat 18 eyes with severe glaucoma postoperative intraocular pressure was equal to or less than $20 \mathrm{~mm} \mathrm{Hg}$ in 14 of 18 eyes, although nine of the 14 successful cases required postoperative medical therapy. Treatment of more than 180 degrees was necessary for sufficient lowering of the intraocular pressure. Complications included transient vitreous hemorrhage (2 eyes), transient choroidal detachment (2 eyes), and hypotony (1 eye).

Zarbin MA et al ${ }^{69}$ in their study of 42 eyes with severe glaucoma that could not be managed successfully by medical therapy and conventional glaucoma surgery did endolaser photocoagulation and followed-up till 36 months (mean, 13 months). After one or two (7 eyes) treatment sessions, 11 eyes (26\%) had an IOP less than $21 \mathrm{~mm} \mathrm{Hg}$ without medications; 21 eyes (50\%) had an IOP less than $21 \mathrm{~mm}$ Hg with medications; 5 eyes (12\%) had an IOP of 21 to $25 \mathrm{~mm} \mathrm{Hg}$ with or without medications; and 5 eyes (12\%) had an IOP greater than $25 \mathrm{~mm}$ Hg. Twenty-three (72\%) of 32 patients were able to discontinue carbonic anhydrase inhibitors.

\section{Transpupillary Cyclophotocoagulation}

In patients who have visible ciliary processes, it is sometimes possible to deliver argon laser energy directly to the anterior 
surface of the ciliary processes. Transpupillary cyclophotocoagulation is performed with a slit-lamp delivery system through a Goldmann three-mirror lens. ${ }^{68,79}$ This technique is most useful in patients with traumatic aniridia or with very large sector iridectomies. ${ }^{80}$ Scleral indentation with a contact lens is of great help during the procedure. However viewing the ciliary processes is not possible in many glaucomatous eyes especially those on long-term miotic therapy thereby signaling an important limitation of the procedure. In patients with advanced neovascular glaucoma, the iris is sometimes pulled anteriorly and peripherally, allowing a view of the ciliary processes. ${ }^{81}$ Trans pupillary CPC through peripheral iridectomy or widely dilated pupil can be effective in treating ciliary block (malignant) glaucoma. ${ }^{82}$ In this case ciliary body ablation through the transpupillary route causes shrinkage and retraction of the ciliary body and normalization of the misdirected flow. The transpupillary cyclophotocoagulation can either be performed using the argon green or the frequency doubled Nd:YAG laser.

The long-term pressure control achieved by treating the anterior ciliary processes is rather short. The treatment is usually performed using an argon laser with duration of 0.1 to 0.2 seconds, a spot size of 50 to $200 \mu \mathrm{m}$, and a starting power of about 500-1000 mW; which is increased until a visible burn is observed. It takes three to four applications to coagulate all visible portion of a ciliary process. The endpoint consists of blanching of the ciliary body, blisters/effusion of the pigment.

Results of transpupillary cyclophotocoagulation are variable. Merritt JC ${ }^{79}$ treated 7 eyes of 6 patients with transpupillary photocoagulation. Only one patient showed a decrease in intraocular pressure to a normal level. This patient was the only one in this series in whom large numbers of ciliary processes could be coagulated. The limiting factor in effective transpupillary argon laser photocoagulation may, therefore, be the total number of ciliary processes visualized and treated.

Results of Shields $\mathrm{S}$ et $\mathrm{al}^{81}$ is also not promising. Out of twenty-seven patients with glaucoma who underwent transpupillary argon laser cyclophotocoagulation only six patients (22.3\%) had a successful outcome, and in many cases the postoperative course was complicated by an additional, sustained increase in intraocular pressure.

Lee $\mathrm{P} \mathrm{F}^{83,84}$ in their series did cyclophotocoagulation taking pit rather than whitening of the ciliary process as end point. Fifteen out of 22 patients showed 50\% reduction in IOP.

Kim DD et $\mathrm{al}^{80}$ reported a patient with traumatic glaucoma who underwent transpupillary argon laser cyclophotocoagulation (TALC) for management of uncontrolled intraocular pressure (IOP) despite maximally tolerated medical therapy. Ten weeks after TALC, the patient's IOP remained controlled with medications at $16 \mathrm{~mm} \mathrm{Hg}$, and visual acuity had improved to 20/25 with an aphakic contact lens. So, in selected patients whose ciliary processes are visible with indirect gonioscopy due to the defect in the iris, TALC may be an effective alternative cyclodestructive procedure to lower IOP when conventional medical or laser treatments are not successful.

Overall cyclophotocoagulation is a definitive advancement over previous modes of cilioablation. However it is an unpredictable procedure with a narrow therapeutic window, and the results are not reproducible. One should thus be careful while doing this procedure.

\section{POSTOPERATIVE MANAGEMENT}

These procedures unlike cyclocryotherapy are less painful.

- At the end of the procedure, subconjunctival corticosteroids are usually administered and patching done for approximately 6 hours.

- The patient should be placed on topical cycloplegics, antibiotics and corticosteroids, which are tapered as the inflammation subsides.

- Preoperative antiglaucoma medications glaucoma medications are continued until the effect of the procedure can be determined. The cholinergic drugs are avoided.

- Sometimes very strong analgesic is required and at times one may have to use narcotic analgesics.

- Follow-up at 1 hour, 1 day, 1 week, 1 month and then according to the response.

- Additional therapy should be considered if needed after one month. ${ }^{85}$ Interventions include drainage device, trabeculectomy, cyclocryotherapy and enucleation.

\section{COMPLICATIONS}

1. Marked pain

2. Mild to severe iritis, synechiae and pupillary block

3. Transient rise of IOP

4. Hypotony

5. Phthisis bulbi

6. Conjunctival surface burn

7. Lens and zonular damage

8. Reduced accommodation

9. Posterior capsule fibrosis in pseudophakia

10. Pupillary distortion

11. Corneal graft failure

12. Scleral thinning and staphyloma

13. Malignant glaucoma

14. Macular edema

15. Retinal detachment

16. Serous and hemorrhagic choroidal detachment

17. Intraocular hemorrhage

18. Best corrected vision loss

19. Sympathetic ophthalmia

20. Endophthalmitis and panophthalmitis

21. Treatment failure

22. Inadvertent sclerostomy 
Cyclodestructive procedures share similar risks, but they vary in degree of risk. The most troubling and common complication of these procedures is a decrease in visual acuity. This can result from a variety of causes, including hypotony, macular edema, and cataract. Due to risk of vision loss makes, cyclodestructive procedures are a last resort in patients with good vision. Less intense laser therapy on a repeated basis rather than a single high dose treatment is suggested to minimize complications of treatment.

Schuman et $\mathrm{al}^{33}$ in their study of 116 eyes treated by contact Nd:YAG TCP, had 19 eyes (16\%) that progressed to NLP and 17 of 36 eyes (47\%) having 20/200 or better vision lost 2 or more Snellen lines. In addition, nine out of 116 eyes (8\%) developed hypotony (IOP of $3 \mathrm{~mm} \mathrm{Hg}$ or less). Many of these hypotonous eyes were also considered to be phthisical.

In Jennings's ${ }^{86}$ series complications included anterior uveitis (42\%), conjunctival injection (36\%), pain (30\%), and conjunctival hemorrhage (15\%). Corneal edema, intraocular pressure spikes, and corneal epithelial defects were each noted in $9 \%$ of the eyes treated, whereas cataracts developed in $12 \%$ of the eyes. Two out of 33 eyes (6\%) developed anterior segment ischemia with subsequent phthisis bulbi. Seven out of 33 eyes (21\%) demonstrated no adverse reactions.

Destroying the correct amount of the ciliary body is not a precise procedure. In eyes with minimal aqueous outflow, a small change in aqueous production can cause marked changes in lOP. If too much ciliary function is destroyed, the patient can develop hypotony (and perhaps phthisis). The risk of hypotony varies among studies, but it appears to be higher with cyclocryotherapy than with laser procedures. The risk of phthisis increases with each subsequent procedure performed.

The cyclodestructive procedures lead to increase in inflammation especially with cyclocryotherapy. Laser procedures generally cause less inflammation. Eyes will often experience chronic aqueous flare after these procedures because of a breakdown in the blood-aqueous barrier.

Pain is a significant feature of cyclocryotherapy. A decrease in pain is the single most obvious advantage of laser procedures over cyclocryotherapy. Hyphema is also a common side effect in patients with neovascular glaucoma. Pressure spikes during and after cyclocryotherapy are also common. The postoperative rise in IOP peaks at about 6 hours.

Surface burns occur with noncontact laser procedures and they can occur with contact lasers if debris is present on the end of the fiberoptic because the debris can absorb the laser energy and heat up.

There have been several published reports of sympathetic ophthalmia (SO) following transscleral cyclophotocoagulation (TSCPC) ${ }^{87-89} \mathrm{Lam}$ et $\mathrm{al}^{88}$ reported that the incidence of $\mathrm{SO}$ at their institution was 5.8\% (four of 69) and $0.67 \%$ (one of 150) after noncontact and contact Nd:YAG cyclophotocoagulation, respectively. Bechrakis et al ${ }^{89}$ have reported a case of sympathetic ophthalmia after 20 months of treatment with 3 sessions of contact Nd:YAG laser cyclophotocoagulation and 1 session of cyclocryotherapy in a case of secondary glaucoma with Coat's disease without any previous history of penetrating trauma or surgery, confirmed by classical histopathology of Sympathetic Ophthalmia (SO), thickening of choroid by lymphocytic infiltration with OKT3 positive mature T cells and Dalen Fuchs' nodules. Disintegration of uveal tissue seems to trigger a cellular immune response against uveal autoantigens possibly by release of high energy in a small spot, results in an explosion like reaction. Also postulated that these eyes being end-stage glaucomatous may itself be a risk factor for developing $\mathrm{SO}^{88}$

Malignant glaucoma has been reported both after diode laser $\mathrm{TCP}^{90}$ and after contact and noncontact Nd:YAG cyclophotocoagulation. ${ }^{91,92}$

A case of panophthalmitis has also been reported after contact diode laser cyclophotocoagulation in a patient with failed trabeculectomy and trabeculotomy for congenital glaucoma. ${ }^{93}$

About 3 to $5 \%$ of the power of laser reaches posterior pole as shown by a study by Jonathan et al. ${ }^{94}$ Noncontact Nd:YAG cyclophotocoagulation had significantly higher transmission compared to Contact Nd:YAG and diode lasers. Exposure energies may approach or exceed ACGIH (American Conference of Governmental Industrial Hygienists) guidelines. Clinical significance of such exposure however is still not proven. It has till yet not proved to be a source of visual loss in any patient. ${ }^{95}$

Pupillary distortion has also been described after DLCP due to injury to peripheral iris caused by anterior displacement of laser spots. ${ }^{96}$

Administration of $100 \mathrm{~J}$ with a Nd:YAG laser increases corneal touch threshold and causes a significant decrease in number, but not diameter, of major corneal nerve bundles. ${ }^{97}$ Nerve damage and corneal hypoesthesia are etiologic factors in ulcerative keratitis following Nd:YAG cyclophotocoagulation. ${ }^{95}$ Results of the preliminary study by Raivio VE et al ${ }^{98}$ suggest that cyclophotocoagulation with the $670 \mathrm{~nm}$ diode laser does not impair corneal innervation.

A case of inadvertent sclerostomy following repeated contact diode laser cyclophotocoagulation has also been reported. ${ }^{99}$

There are practically no differences as far as the contact and noncontact transscleral methods for laser cyclophotocoagulation are concerned both using diode and Nd: YAG lasers in control of IOP, pain, laser induced inflammatory reaction, phthisis bulbi (rate around 10\%), and postlaser decline in visual function (around 40\%). ${ }^{100}$

\section{CONCLUSIONS AND FUTURE DIRECTIONS}

The concept of cycloablation has been present for several decades, but the inability to titrate a predictable and reproducible 
response has been its drawback. However, Cyclodestructive procedures still plays an important role in our paradigm of glaucoma therapy, since it is the last resort treatments for intractable glaucomas in eyes who have failed trabeculectomy or tube shunt procedures, eyes with minimal useful vision and elevated intraocular pressure, and eyes who have no visual potential and need pain relief.

The therapeutic window for all types of cycloablative procedures is low. Therefore too aggressive a treatment can lead to hypotony and phthisis and too little treatment will have no effect on IOP reduction. The variability in the location of the ciliary processes may account for the variable response to same degrees of treatment in different patients.

Cyclocryotherapy was the most commonly used method previously but it has now been replaced by laser cyclophotocoagulation, which causes less pain and is associated with less inflammation, hypotony, and phthisis. This is because of cryotherapy's frequent complications and unpredictable degree of pressure lowering. With cyclocryotherapy, the volume of ciliary body destroyed is much greater as there is much larger spread of the cold associated with the procedure. Experience with Nd:YAG or diode endolaser cyclophotocoagulation holds promise for these and other patients because it appears to provide good results and lesser side effects. Laser cyclophotocoagulation is at present the least traumatic cyclodestructive procedure. The transscleral laser procedures are simple office procedures and they continue to form an important instrument in antiglaucoma armamentarium. Transscleral diode cyclophotocoagulation with G- probe is the procedure of choice and most commonly used laser procedure because it is noninvasive and does not require a clear cornea or widely dilated pupil. Additional experience will better define the indications and scope of these newer modalities of cycloablation. In addition the call for these modalities will keep on rising in the future with the increasing use of silicon oil for complicated retinal detachments and also as a primary procedure for retinal detachment and silicon oil induced glaucomas.

The future laser procedures will see more refined parameters, to minimize collateral tissue damage, newer laser delivery systems, and novel applications of existing technology.

\section{REFERENCES}

1. Bietti G. Surgical intervention on the ciliary body; new trends for the relief of glaucoma. JAMA 1950;142:889-97.

2. Meyer SJ. Diathermy cauterization of ciliary body for glaucoma. Am J Opthalmol 1948;31:1504-07.

3. Walton DS, Grant WM. Penetrating cyclodiathermy for filtration. Arch Ophthalmol 1970;83:47-48.

4. Haik GM, Breffeilh LA, Barbar A. Bete irradiation as a possible therapeutic agent in glaucoma: An experimental study with report of a clinical case. Am J Ophthalmol 1948;31:945.

5. Berens C, Sheppard LB, Duel AB Jr. Cycloelectrolysis for glaucoma. Trans Am Ophthalmol Soc 1949;47:364.
6. DeRoeth A Jr. Cryosugery for the treatment of advanced simple glaucoma. Am J Ophthalmol 1968;66:1034-41.

7. Bellows AR, Grant WM. Cryotherapy in advanced inadequately controlled glaucoma. Am J Ophthalmol 1973;75:679-84.

8. Caprioli J, Strang SL, Spaeth GL, et al. Cyclocryotherapy in treatment of advanced glaucoma. Ophthalmology 1985;92:94753.

9. Bellows AR, Grant WM. Cyclocryotherapy of chronic openangle glaucoma in aphakic eyes. Am J Ophthalmol 1978;85:61521.

10. Polack PJ, et al. Histologic effects of contact ultrasound for the treatment of glaucoma. Invest Ophthalmol Vis Sci. 1991;32:2136-42.

11. Finger PT, et al. Transscleral microwave cyclodestruction. Invest Ophthalmol Vis Sci 1990;31:2151-55.

12. Beckman H, Kinoshita A, Rata An, et al. Transscleral ruby laser irradiation of the ciliary body in the treatment of intractable glaucoma. Trans Am Acad Ophthalmol Otol 1972;76:423-36.

13. Beckman H, Sugar HS. Neodymium laser cyclocoagulation. Arch Ophthalmol 1973;90:27-28.

14. Shields MB: Cyclodestructive surgery for glaucoma: Past, present, and future, Trans Am Acad Ophthalmol Otolaryngol 1985;83:285-303.

15. Mastrobattista JM, Luntz M. Ciliary body ablation: Where are we and how did we get here. Surv Ophthalmol 1996;41:193213.

16. Caprioli J et al: Cyclocryotherapy in the treatment of advanced glaucoma. Ophthalmology 1985;92:947-54.

17. van der Zypen E, et al. The effects of transscleral laser cyclophotocoagulation on rabbit ciliary body vascularization. Graefes Arch Clin Exp Ophthalmol 1989;227:172.

18. Schubert HD, Federman JL. A comparison of CW Nd:YAG contact transscleral cyclophotocoagulation with cyclocryopexy. Invest Ophthalmol Vis Sci Mar 1989;30(3):536-42.

19. Cantor LB, et al. Neodymium-YAG transscleral cyclophotocoagulation- the role of pigment. Invest Ophthalmol Vis Sci 1989;30:1834-37.

20. Schubert HD, Agarwala A, Arbizo V. Changes in aqueous outflow after in vitro neodymium: Yttrium aluminum garnet laser cyclophotocoagulation. Invest Ophthalmol Vis Sci Sep 1990;31(9):1834-38.

21. Liu GJ, Mizukawa A, Okisaka S. Mechanism of intraocular pressure decrease after contact transscleral continuous-wave Nd:YAG laser cyclophotocoagulation. Ophthalmic Res 1994;26(2):65-79.

22. Stewart WC. Clinical practice of glaucoma.1990, Slack publishers.

23. Alward WLM: Laser cyclophotocoagulation. In Weingeist TA, Sneed SR (Eds): Laser surgery in ophthalmology: Practical applications, East Norwalk, Conn., Appleton and Lange, 1992.

24. SchumanJS et al: Contact transscleral continuous wave Nd:YAG laser cyclophotocoagulation. Ophthalmology 1990;97:571-80.

25. Wilensky JT, Welch D, Mirolovich M: Transscleral cyclophotocoagulation using a Nd:YAG laser. Ophthalmic Surg 1985;16:95-98.

26. Shields MB, Shields SE. Noncontact transscleral Nd:YAG cyclophotocoagulation: A long-term follow-up of 500 patients. Trans Am Ophthalmol Soc 1994;92:271-83; discussion 283-87. 
27. Lin P, Wollstein G, Glavas IP, et al. Contact transscleral neodymium: Yttrium-aluminum-garnet laser cyclophotocoagulation Long-term outcome. Ophthalmology. Nov 2004;111(11):2137-43.

28. Phelan MJ, Higginbotham EJ. Contact transscleral Nd:YAG laser cyclophotocoagulation for the treatment of refractory pediatric glaucoma. Ophthalmic Surg Lasers. Sep-Oct 1995;26(5):401-03.

29. Delgado MF, Dickens CJ, Iwach AG, et al. Long-term results of noncontact neodymium: Yttrium-aluminum-garnet cyclophotocoagulation in neovascular glaucoma. Ophthalmology. May 2003;110(5):895-99.

30. Beiran I, Rootman DS, Trope GE, et al. Long-term results of transscleral Nd:YAG cyclophotocoagulation for refractory glaucoma postpenetrating keratoplasty. J Glaucoma Jun 2000;9(3):268-72.

31. Cohen EJ, Schwartz LW, Luskind RD, et al. Neodymium:YAG laser transscleral cyclophotocoagulation for glaucoma after penetrating keratoplasty. Ophthalmic Surg 1989;20:713-16.

32. Threlkeld AB, Shields MB. Noncontact transscleral Nd:YAG cyclophotocoagulation for glaucoma after penetrating keratoplasty. Am J Ophthalmol 1995;120:569-76.

33. Schuman JS, Bellows AR, Shingleton BJ, et al. Contact transscleral Nd:YAG laser cyclophotocoagulation: Midterm results. Ophthalmology 1992;99:1089-95.

34. Schuman JS, Puliafito CA, Allingham RR, et al. Contact transscleral continuous wave neodymium:YAG laser cyclophotocoagulation. Ophthalmology. May 1990;97(5):57180.

35. Miyazaki M, Hoya T. Effects of transscleral Nd:YAG laser cyclophotocoagulation: Research for a new manner of treatment. Ophthalmologica 1994;208:122-30.

36. Hampton C, Chields MB, Miller KN, et al. Evaluation of a protocol for transscleral neodymium: YAG cyclophotocoagulation in one hundred patients. Ophthalmology 1990;97:910-17.

37. Brancato R, Giovanni L, Trabucchi G, et al. Contact transscleral cyclophotocoagulation with Nd:YAG laser in uncontrolled glaucoma. Ophthalmic Surg Aug 1989;20(8):547-51.

38. Klapper RM, Wandel T, Donnenfeld E, et al. Transscleral neodymium:YAG thermal cyclophotocoagulation in refractory glaucoma. A preliminary report. Ophthalmology Jun 1988;95(6):719-22.

39. Hennis HL, Stewart WC: Semiconductor diode laser transscleral cyclophotocoagulation in patients with glaucoma. Am J Ophthalmol 1992;113:81-85.

40. Agarwal HC, Gupta V, Sihota R. Evaluation of contact versus noncontact diode laser cyclophotocoagulation for refractory glaucomas using similar energy settings. Clin Experimental Ophthalmol Feb 2004;32(1):33-38.

41. Lai JS, Tham CC, Chan JC, et al. Diode laser transscleral cyclophotocoagulation in the treatment of chronic angle-closure glaucoma: A preliminary study. J Glaucoma Aug 2003; 12(4):360-64.

42. Murphy CC, Burnett CA, Spry PG, et al. A two centre study of the dose-response relation for transscleral diode laser cyclophotocoagulation in refractory glaucoma. Br J Ophthalmol Oct 2003;87(10):1252-57.
43. Kramp K, Vick HP, Guthoff R. Transscleral diode laser contact cyclophotocoagulation in the treatment of different glaucomas, also as primary surgery. Graefes Arch Clin Exp Ophthalmol Sep 2002;240(9):698-703.

44. Schlote T, Derse M, Rassmann K, et al. Efficacy and safety of contact transscleral diode laser cyclophotocoagulation for advanced glaucoma. J Glaucoma Aug 2001;10(4):294-301.

45. Kirwan JF, Shah P, Khaw PT. Diode laser cyclophotocoagulation: Role in the management of refractory pediatric glaucomas. Ophthalmology Feb 2002;109(2):316-23.

46. Schlote T, Derse M, Zierhut M. Transscleral diode laser cyclophotocoagulation for the treatment of refractory glaucoma secondary to inflammatory eye diseases. Br J Ophthalmol Sep 2000;84(9):999-1003.

47. Semchyshyn TM, Tsai JC, Joos KM. Supplemental transscleral diode laser cyclophotocoagulation after aqueous shunt placement in refractory glaucoma. Ophthalmology Jun 2002;109(6):107884.

48. Kumar A, Dada T, Singh RP, Kedar S. Diode laser transscleral cyclophotocoagulation for glaucoma following silicone oil removal. Clin Experimental Ophthalmol Aug 2001;29(4):22024.

49. Han SK, Park KH, Kim DM, et al. Effect of diode laser transscleral cyclophotocoagulation in the management of glaucoma after intravitreal silicone oil injection for complicated retinal detachments. Br J Ophthalmol Jun 1999;83(6):713-17.

50. Autrata R, Rehurek J. Long-term results of transscleral cytophotocoagulation in refractory pediatric glaucoma patients. Ophthalmologica Nov-Dec 2003;217(6):393-400.

51. Wong EY, Chew PT, Chee CK, et al. Diode laser contact transscleral cytophotocoagulation for refractory glaucoma in Asian patients. Am J Ophthalmol Dec 1997;124(6):797-804.

52. Kosoko O, Gaasterland DE, Pollack IP, Enger CL. Long-term outcome of initial ciliary ablation with contact diode laser transscleral cyclophotocoagulation for severe glaucoma. The Diode Laser Ciliary Ablation Study Group. Ophthalmology Aug 1996;103(8):1294-302.

53. Bloom PA, Tsai JC, Sharma K, Miller MH, Rice NS, Hitchings RA, Khaw PT. Cyclodiode transscleral diode laser cyclophotocoagulation in the treatment of advanced refractory glaucoma. Ophthalmology Sep 1997;104(9):1508-19.

54. Spencer AF, Vernon SA. "Cyclodiode": Results of a standard protocol. Br J Ophthalmol Mar 1999;83(3):311-16.

55. Werner A, Vick HP, Guthoff R. Cyclophotocoagulation with the diode laser. Study of long-term results Ophthalmologe. Mar 1998;95(3):176-80.

56. Pucci V, Tappainer F, Borin S, et al. Long-term follow-up after transscleral diode laser photocoagulation in refractory glaucoma. Ophthalmologica Jul-Aug 2003;217(4):279-83.

57. Noureddin BN, Zein W, Haddad C, Ma'luf R, Bashshur Z. Diode laser transcleral cyclophotocoagulation for refractory glaucoma: a 1 year follow-up of patients treated using an aggressive protocol. Eye 2005 Apr 29 (Epub ahead of print).

58. Ocakoglu O, Arslan OS, Kayiran A. Diode laser transscleral cyclophotocoagulation for the treatment of refractory glaucoma after penetrating keratoplasty. Curr Eye Res Jul 2005;30(7):56974 . 
59. Gupta V, Agarwal HC. Contact transscleral diode laser cyclophotocoagulation treatment for refractory glaucomas in the Indian population. Indian J Ophthalmol Dec 2000;48(4):295300.

60. Levinger E, Segev E, Geyer O. Diode laser cyclophotocoagulation in refractory glaucoma. Harefuah Jul 2003; 142(7):500-2:568-67.

61. Mistlberger A, Liebmann JM, Tschiderer H, et al. Diode laser transscleral cyclophotocoagulation for refractory glaucoma. J Glaucoma Aug 2001;10(4):288-93.

62. Kivela T, Puska P, Raitta C, et al. Clinically successful contact transscleral krypton laser cyclophotocoagulation. Long-term histopathologic and immunohistochemical autopsy findings. Arch Ophthalmol Nov 1995;113(11):1447-53.

63. Raivio VE, Immonen IJ, Puska PM. Transscleral contact krypton laser cyclophotocoagulation for treatment of glaucoma in children and young adults. Ophthalmology Oct 2001; 108(10):1801-07.

64. Raivio VE, Immonen IJ, Laatikainen LT, et al. Transscleral contact krypton laser cyclophotocoagulation for treatment of post-traumatic glaucoma. J Glaucoma Apr 2001;10(2):77-84.

65. Di Staso S, Genitti G, Verolino M, et al. Trans-scleral krypton laser cyclophotocoagulation: Our experience of its use on patients with neovascular glaucoma. Acta Ophthalmol Scand Suppl 1997;(224):37-38.

66. Patel A, Thompson JT, Michels RG, et al: Endolaser treatment of the ciliary body for uncontrolled glaucoma. Ophthalmology 1986;93:825-30.

67. Lin S. Endoscopic cyclophotocoagulation. Br J Ophthalmol. Dec 2002;86(12):1434-38.

68. Holz HA, Lim MC. Glaucoma lasers: A review of the newer techniques. Curr Opin Ophthalmol Apr 2005;16(2):89-93.

69. Zarbin MA, Michels RG, de Bustros S, et al. Endolaser treatment of the ciliary body for severe glaucoma. Ophthalmology Dec 1988;95(12):1639-48.

70. Chen J, Cohn RA, Lin SC, et al. Endoscopic photocoagulation of the ciliary body for treatment of refractory glaucomas. Am J Ophthalmol Dec 1997;124(6):787-96.

71. Uram M. Ophthalmic laser microendoscope ciliary process ablation in the management of neovascular glaucoma. Ophthalmology 1992;99:1823-28.

72. Uram M. Combined phacoemulsification, endoscopic ciliary process photocoagulation, and intraocular lens implantation in glaucoma management. Ophthalmic Surg 1995;26:346-52.

73. Gayton JL, Van Der Karr M, Sanders V. Combined cataract and glaucoma surgery: Trabeculectomy versus endoscopic laser cycloablation. J Cataract Refract Surg Sep 1999;25(9):121419.

74. Neely DE, Plager DA. Endocyclophotocoagulation for management of difficult pediatric glaucomas. J AAPOS. Aug 2001;5(4):221-29.

75. Lima FE, Magacho L, Carvalho DM, et al. A prospective, comparative study between endoscopic cyclophotocoagulation and the Ahmed drainage implant in refractory glaucoma. J Glaucoma. Jun 2004;13(3):233-37.

76. Lin SC, Chen MJ, Lin MS, et al. Vascular effects on ciliary tissue from endoscopic versus transscleral cytophotocoagulation. Br. J Ophthalmol Apr 2006;90(4):496-500.
77. Barkana Y, Morad Y, Ben-nun J. Endoscopic photocoagulation of the ciliary body after repeated failure of transscleral diodelaser cyclophotocoagulation. Am J Ophthalmol 2002; 133(3):405-07.

78. Lim JI, Lynn M, Capone A Jr, et al. Ciliary body endophotocoagulation during pars plana vitrectomy in eyes with vitreoretinal disorders and concomitant uncontrolled glaucoma. Ophthalmology Jul 1996;103(7):1041-46.

79. Merritt JC. Transpupillary photocoagulation of the ciliary processes. Ann Ophthalmol Mar 1976;8(3):325-28.

80. Kim DD, Moster MR. Transpupillary argon laser cyclophotocoagulation in the treatment of traumatic glaucoma. $\mathrm{J}$ Glaucoma Oct 1999;8(5):340-41.

81. Shields S, Stewart WC, Shields MB. Transpupillary argon laser cyclophotocoagulation in the treatment of glaucoma. Ophthalmic Surg Mar 1988;19(3):171-75.

82. Herschler J. Laser shrinkage of the ciliary process. A treatment for malignant (ciliary block) glaucoma. Ophthalmology 1980; 87:1155-59.

83. Lee PF: Argon laser photocoagulation of the ciliary processes in cases of aphakic glaucoma, Arch Ophthalmol 1979;97:213538.

84. Lee PF, Shihab Z, Eberle M. Partial ciliary process laser photocoagulation in the management of glaucoma. Lasers Surg Med 1980;1(1):85-92.

85. Schuman JS, Puliafito CA. Laser cyclophotocoagulation. Int Ophthalmol Clin 1990;30:111-91.

86. Jennings BJ, Mathews DE. Complications of neodymium:YAG cyclophotocoagulation in the treatment of open-angle glaucoma. Optom Vis Sci Oct 1999;76(10):686-91.

87. Edward DP, Brown SVL, Higginbothom E, et al. Sympathetic ophthalmia following neodymium:YAG cyclotherapy. Ophthalmic Surg 1989;20:544-46.

88. Lam S. Tessler HH, Lam BL, et al. High incidence of sympathetic ophthalmia after contact and noncontact neodymium:YAG cyclotherapy. Ophthalmology 1992;99:1818-22.

89. Bechrakis NE, Müller-Stolzenurg NW, Helbig, et al. Sympathetic ophthalmia following laser cyclophotocoagulation. Arch Ophthalmol 1994;112:80-84.

90. Azuara Blanco A, Dua H S. Malignant glaucoma after diode laser cyclophotocoagulation. Am J Ophthalmol 1999;127:46769.

91. Harden DR, Brown JD. Malignant glaucoma after Nd:YAG cyclophotocoagulation. Am J Ophthalmol 1991;111:245-47.

92. Wand M, Schuman JS, Pulinfito CA, et al. Malignant glaucoma after contact transscleral Nd:YAG laser cyclophotocoagulation. J Glaucoma 1993;2:110-11.

93. Venkatesh P, Gogoi M, Sihota R, et al. Panophthalmitis following contact diode laser cyclophotocoagulation in a patient with failed trabeculectomy and trabeculotomy for congenital glaucoma. Br J Ophthalmol 2003;87(4):508.

94. Jonathan S Myers, M G trevisani, N Imami, et al. Laser reaching posterior pole during transscleral cyclophotocoagulation. Arch Ophthalmol 1998;116:488-91.

95. Pastor SA, Singh K, Lee DA, et al. Cytophotocoagulation: A report by the American Academy of Ophthalmology. Ophthalmology Nov 2001;108(11):2130-38. 
96. Torsten S, Derse M, Thiel HJ, et al. Pupillary distortion after transscleral Diode laser cyclophotocoagulation. Br J Ophthalmol. 2000;84:337-38.

97. Weigt AK, Herring IP, Marfurt CF, et al. Effects of cyclophotocoagulation with a neodymium: Yttrium-aluminumgarnet laser on corneal sensitivity, intraocular pressure, aqueous tear production, and corneal nerve morphology in eyes of dogs. Am J Vet Res. Jun 2002;63(6):906-15.

98. Raivio VE, Vesaluoma MH, Tervo TM, et al. Corneal innervation, corneal mechanical sensitivity, and tear fluid secretion after transscleral contact $670 \mathrm{~nm}$ diode laser cyclophotocoagulation. J Glaucoma. Oct 2002;11(5):446-53.

99. Gupta V, Sony P, Sihota R, et al. Inadvertent sclerostomy with encysted bleb following transscleral contact diode laser cytophotocoagulation. Clin. Experimental Ophthalmol. Jan-Feb 2006;34(1):86-87.

100. Schwartz GP, Schwartz LW, Spaeth GL: Laser cyclodestructive procedures of the ciliary body; in Fankhauser F, Kwasniewska
S (Eds): Lasers in Ophthalmology: Basic, Diagnostic, Surgical Aspects-A Review. Amsterdam, Kugler, 2003;341-51.

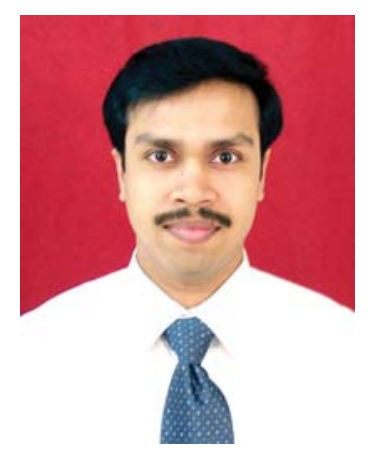

Subrata Mandal (drsubratamandal@gmail.com)

"I don't know what your destiny will be, but one thing I do know: the ones among you who will really be happy are those who have sought and found how to serve." 